\title{
ESTRESSE HÍDRICO EM PLANTIO DE Eucalyptus grandis VS. Eucalyptus urophylla, EM FUNÇÃO DO SOLO, SUBSTRATO E MANEJO HÍDRICO DE VIVEIRO ${ }^{1}$
}

\author{
Jane Luísa Wadas Lopes², Iraê Amaral Guerrini ${ }^{3}$, Magali Ribeiro da Silva ${ }^{3}$, João Carlos Cury Saad ${ }^{4}$ e \\ Cristiano Freitas Lopes ${ }^{5}$
}

\begin{abstract}
RESUMO - O objetivo deste trabalho foi avaliar em campo os níveis de estresse hídrico das mudas de Eucalyptus grandis vs. Eucalyptus urophylla selecionado para tolerância ao déficit hídrico, em função dos substratos, do manejo hídrico e dos solos. As mudas foram produzidas em dois viveiros distintos do Estado de São Paulo: com o substrato Plantmax estacas ${ }^{\circledR}$ (PLX) em Bofete (SP) e com a mistura em partes iguais de casca de arroz carbonizada e vermiculita (CAC), em Ibaté (SP). A partir dos 60 dias após a estaquia (DAE), durante a rustificação as mudas foram manejadas com cinco frequências de irrigação por subsuperfície: F1 - irrigado uma vez ao dia, F2 - irrigado duas vezes ao dia, F3 - irrigado três vezes ao dia, F4 - irrigado quatro vezes ao dia e FD - mantido em irrigação, restabelecendo a capacidade de campo até o plantio aos 90 DAE, em um solo argiloso e outro arenoso. Foram realizadas avaliações dos níveis de estresse (brando, moderado e severo), que afetaram a sobrevivência nos dois solos, por meio de censo aos 15 e aos 30 dias após o plantio. Com relação aos níveis de estresse avaliados, verificou-se pouca influência do substrato, porém onde ocorreu o PLX proporcionou menores percentuais de plantas afetadas. Independentemente do tipo de solo onde as mudas foram plantadas, os sintomas de estresse nas plantas, de modo geral, foram semelhantes. O manejo de viveiro não influenciou na sobrevivência das mudas, embora tenham ocorrido algumas diferenças estatísticas quando se usaram CAC e plantio no solo arenoso, porém sem tendência clara de comportamento. Os critérios relativos à implantação foram mais determinantes na sobrevivência das mudas no campo até os 30 dias após o plantio, indicando a necessidade de replantio.
\end{abstract}

Palavras-chave: Solo arenoso, Solo argiloso e Manejo hídrico por subsuperfície.

\section{WATER STRESS IN THE PLANTING OF Eucalyptus grandis $X$ Eucalyptus urophylla, DUE TO SOIL, SUBSTRATE AND WATER MANAGEMENT}

\begin{abstract}
The objective of this work was to evaluate the levels of water stress in Eucalyptus grandis $x$ Eucalyptus urophylla seedlings selected for water deficiency, considering substrate water management and types of soil. The seedlings were produced in two distinct nurseries: the Plantmax estacas ${ }^{\circledR}$ substrate $(P L X)$ in Bofete(SP) and in a mix with equal proportions of rice carbonized husks and vermiculite (CAC) in Ibaté (SP). Sixty days after cutting (DAE) and farther, during hardening, the seedlings were managed with five underwater irrigations, restoring the field conditions: F1: irrigated once a day, F2: irrigated twice a day, F3: irrigated three times a day, F4: irrigated four times a day and FD: maintained under irrigation, until water saturation until planting at 90 DAE, in a clayie soil and in a sandy soil. Evaluations on the low, moderate and high water stress levels that affect survival in the two types of soil at 15 and 30 days after planting. Little influence of substrates to the water stress levels was observed. However, a lesser percentual of affected seedlings was observed in PLX. Independent of the type of similar symptoms of water stress was observed, independently of type of soil. Nursery management does not affect seedling survival, even though statistical differences were detected when CAC and sandy soil were tested, however, without clear seedlings performance. Factors related to the planting process were more important on the field seedlings survival, until 30 days after planting, exhibiting the necessity of planting again.
\end{abstract}

Keywords: Sandy soil, Clayie soil and Underwater management.

\footnotetext{
${ }^{1}$ Recebido em 07.07.2008 e aceito para publicação em 25.08.2010.

${ }^{2}$ Doutora em Agronomia pela Universidade Estadual Paulista, UNESP/FCA, Botucatu, SP. E-mail: <jane.luisa@uol.com.br>. ${ }^{3}$ Departamento de Recursos Naturais/Ciência do Solo da UNESP/FCA, Botucatu-SP. E-mail: <iguerrini@fca.unesp.br>e <magaliribeiro@fca.unesp.br>.

${ }^{4}$ Departamento de Engenharia Rural da Universidade Estadual Paulista, UNESP/FCA, Botucatu, SP. E-mail: <joaosaad@fca.unesp.br>.

${ }^{5}$ Duratex, Fazenda Rio Claro, Lençóis Paulista, SP. E-mail: <cristiano.lopes@duratex.com.br>.
} 


\section{INTRODUÇÃO}

As plantas podem sofrer estresses reversíveis ou irreversíveis (LARCHER, 2000) causados por fatores bióticos ou abióticos (FERREIRA e MILANI, 2002; TAIZ e ZEIGER, 2004). A reversibilidade pode ocorrer devido à capacidade elástica dos organismos para suportarem tensões, sendo as funções fisiológicas alteradas por determinado período, retornando à condição normal após a cessação do estresse. Porém, após níveis intensos pode surgir uma tensão plástica e, nesse caso, as alterações provocadas são permanentes, causando danos e até morte (PALLARDY, 1986 apud SILVA, 2003). Assim, a eficiência no uso da água por uma planta pode ser entendida como eficiente mecanismo de evolução adaptativa através do qual esta adquire maior elasticidade para enfrentar possíveis déficits hídricos (LIMA, 1995). Geralmente, qualquer tipo de estresse é medido em relação à sobrevivência das plantas, ao crescimento, à produtividade (FERREIRA e MILANI, 2002; TAIZ e ZEIGER, 2004) ou processos assimilatórios primários como a absorção de $\mathrm{CO}_{2}$ e nutrientes (TAIZ e ZEIGER, 2004).

O déficit hídrico, o estresse provocado pelo calor e o choque térmico, o resfriamento e o congelamento, a salinidade e a deficiência de oxigênio são os principais agentes estressores que restringem o crescimento das plantas. Isso ocorre de tal modo que as produtividades de biomassa agronômica ou florestal, no final da estação, expressam apenas uma fração do seu potencial genético (TAIZ e ZEIGER, 2004), e também a desnutrição, a matocompetição, as pragas e as doenças e os danos mecânicos ou por animais podem estressar as plantas (LOPES et al., 2009).

Algumas espécies de plantas são mais tolerantes ao estresse, outras bem menos, sendo a temperatura do ar um dos fatores mais estressantes, podendo se manifestar em minutos (tanto as altas, quanto as baixas), seguida do vento a umidade do solo pode levar dias e as deficiências minerais do solo, até meses para se manifestar (TAIZ e ZEIGER, 2004). Conforme esses mesmos autores, à medida que a planta tolera, mais o estresse se torna aclimatada, porém não adaptada, pois adaptação se refere a um nível de resistência geneticamente determinado, adquirido por processos de seleção durante muitas gerações. Dessa forma, a adaptação e aclimatação ao estresse ambiental resultam de eventos integrados que ocorrem em todos os níveis de organização, desde o anatômico e morfológico até o celular, bioquímico e molecular.

Quando o déficit hídrico apresenta evolução suficientemente lenta para permitir mudanças nos processos de desenvolvimento, o estresse provocado tem vários efeitos sobre o crescimento, e as espécies de eucalipto podem apresentar diferentes resistências ao déficit de água no solo (TATAGIBA et al., 2007). Isso foi verificado por Merchant et al. (2007), que obtiveram respostas diferentes ao déficit hídrico em seis espécies de eucalipto, e aquelas que se desenvolveram em ambientes de baixa pluviosidade apresentaram menor potencial osmótico e redução do teor de água na folha.

Nas plantas, o estado de energia da água no solo é importante, pois solos de diferentes classes texturais podem ter semelhantes quantidades de água, porém com distintos estados de energia, pois o movimento de água se dá por diferença de potencial, tanto no solo como do solo quanto a planta. Para que as plantas consigam absorver água do solo, as células da epiderme de suas raízes devem estar num potencial mais negativo do que a água que está no solo. A presença de raízes tende a aumentar a velocidade de infiltração, sendo nos solos arenosos a infiltração de água muito maior do que nos solos argilosos, porém a retenção é menor, sendo com a adição ou existência de material orgânico a infiltração favorecida nos horizontes onde a matéria orgânica atua (GONÇALVES et al., 2000). Quando o solo seca, o seu potencial mátrico torna-se mais negativo, porém as plantas continuam a absorver água enquanto o potencial hídrico for menor, pois ocorre ajuste osmótico, ou acumulação de solutos pelas células, fazendo que as plantas consigam manter o turgor e o volume celular. Esse ajuste osmótico desenvolve-se lentamente em resposta à desidratação do tecido, e, assim, pode-se questionar se não seria o resultado de outro fator, como a diminuição da taxa de crescimento, o que poderia evidenciar que seja uma aclimatação que permite à planta tolerar mais o déficit hídrico (TAIZ e ZEIGER, 2004).

O objetivo desta pesquisa foi avaliar os níveis de estresse hídrico sofrido pelas mudas do híbrido de Eucalyptus grandis vs. Eucalyptus urophylla em função dos substratos, dos manejos hídricos e dos tipos de solo onde foram plantados, bem como determinar a porcentagem de mudas mortas em função do déficit hídrico, que define a necessidade ou não do replantio. 


\section{MATERIAL E MÉTODOS}

O experimento foi conduzido de novembro de 2005 a janeiro de 2006, no Estado de São Paulo. As mudas do híbrido H13 selecionado para deficiência hídrica foram produzidas por miniestaquia em dois viveiros distintos: 5.000 mudas com o substrato Plantmax estacas ${ }^{\circledR}$, (PLX), em Bofete e 5.000 mudas com a mistura em partes iguais de casca de arroz carbonizada e vermiculita (CAC), em Ibaté, segundo Lopes (2008).

Aos 60 DAE, foram transferidas para Patrocínio Paulista, acondicionadas em bandejas do "tipo caixa" na densidade de 200 plantas $\mathrm{m}^{-2}$ (com cada planta ocupando $50 \mathrm{~cm}^{2}$ de área), constituindo um delineamento inteiramente casualizado com cinco tratamentos de 1.000 mudas para cada substrato, com quatro repetições de 250 mudas cada, irrigados por subsuperfície (Figura 1), restabelecendo a condição de capacidade de campo dos substratos, na fase de rustificação das mudas, a saber:

1: F1 - irrigado uma vez ao dia, às $13 \mathrm{~h}$;

2: F2 - irrigado duas vezes ao dia, às 10 h30 e às 16h30;

3: F3 - irrigado três vezes ao dia, às 9h30, 13h30 e $17 \mathrm{~h} 30$;

4: F4 - irrigado quatro vezes ao dia, às 8, 11, 14 e $17 \mathrm{~h}$; e

5: FD - mantido em irrigação, com lâmina de 2 cm na parte inferior do tubete.

As lâminas médias brutas de água para as mudas produzidas no substrato CAC foram de 3,50; 5,50; 7,40; 8,50; e 6,30 $\mathrm{mm} \mathrm{dia}^{-1}$ e para as produzidas no PLX de 3,90; 5,00; 6,30; 7,40; e 5,40 mm dia-1 (para F1, F2, F3, F4 e FD, respectivamente). As adubações foram realizadas segundo Lopes (2008).
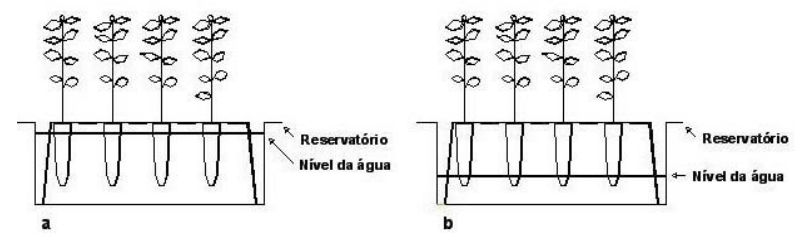

Figura 1 - Representação do sistema de irrigação nos manejos F1, F2, F3 e F4 (a) e no manejo FD- mantido em irrigação (b).

Figure 1 - Irrigation system representation for the management of F1, F2, F3 e F4 (a) and for the FD managementmaintained irrigated (b).
Após 90 DAE, 4.000 mudas de cada substrato foram selecionadas e plantadas em espaçamento de $3 \mathrm{~m}$ entre linhas e $2 \mathrm{~m}$ entre plantas ( $3 \times 2$ ), totalizando 1.667 plantas ha-1, sendo 2.000 de cada substrato em um solo arenoso (TA) de Patrocínio Paulista e 2.000 de cada substrato em um solo argiloso (TB) de Guará, áreas essas com pecuária extensiva de leite e cultivo de soja, respectivamente, antes da implantação do experimento. Nos dois locais foram realizadas as operações de preparo do terreno, a saber: rebaixamento da vegetação (somente para o solo argiloso, usando trator de pneu com roçadeira), controle da matocompetição através da aplicação de herbicida em área total, combate a formigas (gêneros Acromyrmex e Atta) e cupins e subsolagem a $50 \mathrm{~cm}$ de profundidade (com trator de pneu e subsolador).

Antes do plantio, as mudas tiveram seus sistemas radiculares imersos em solução de MAP (calda a 1\%) e cupinicida à base de fipronil (calda a 0,25\%). O plantio foi manual, usando plantadeira tipo matraca, sendo a irrigação efetuada logo em seguida, através de trator de pneu e carreta-pipa, colocando-se 2 L de água não potável por cova. Após quatro dias, efetuou-se uma nova irrigação com a mesma quantia de água. A umidade natural do solo no momento de plantio era de 10,46\% (camada de 0 - $20 \mathrm{~cm}$ ) e 11,92\% (camada de 20 - $40 \mathrm{~cm}$ ) para o solo arenoso e de 23,06\% (camada de 0 - $20 \mathrm{~cm}$ ) e de 26,78\% (camada de 20 - $40 \mathrm{~cm}$ ) no solo argiloso.

A adubação com NPK foi realizada tendo como base a análise de fertilidade dos solos, sendo a dosagem de adubo para cada local (40 kg de $\mathrm{N} \mathrm{ha}^{-1}$ para TB e 60,40 e $50 \mathrm{~kg} \mathrm{ha}^{-1}$ de N-P-K, respectivamente, para TA) determinada segundo as recomendações de Gonçalves (1995).

O delineamento estatístico adotado foi o de blocos ao acaso com quatro repetições. Em cada repetição foram plantadas 96 mudas (8 linhas com 12 plantas em cada uma), obedecendo à mesma distribuição espacial nos tratamentos em ambos os locais.

Aos 15 e aos 30 dias foram realizadas contagens de $100 \%$ das plantas, avaliando-se individualmente os níveis de estresse que afetaram a sobrevivência nos dois solos. Os níveis de déficit hídrico foram definidos previamente e a avaliação, visual, sendo em cada planta observados os sintomas do seguinte modo: déficit brando - gemas apicais da planta com leve murchamento; défict moderado - planta em ponto de murcha; e déficit severo - planta compelo menos uma folha seca ou com sinal de "V invertido".

Revista Árvore, Viçosa-MG, v.35, n.1, p.31-39, 2011 
Analisou-se também a capacidade de retenção de água dos solos sob diferentes níveis de tensão, usando a Placa de Pressão de Richards (RICHARDS, 1949), e a partir dos dados foi calculada a disponibilidade de água nos solos.

Para fins de comparação entre os resultados dos efeitos avaliados, utilizou-se a análise de variância, sendo as médias comparadas pelo teste de Tukey a $5 \%$ de probabilidade.

\section{RESULTADOS E DISCUSSÃO}

Verifica-se na Tabela 1, em todas as tensões de água no solo, que a umidade à base de volume apresentou maior valor no solo argiloso, o que não significa maior disponibilidade de água. Calculando a água disponível em cada tipo de solo, que é o intervalo de umidade entre a capacidade de campo (adotando a umidade correspondente a -0,01 $\mathrm{MPa}$ ) e o ponto de murchamento permanente (-1,5 $\mathrm{MPa})$; em uma profundidade de $1 \mathrm{~m}$, obteve-se que no solo arenoso a disponibilização de água foi de $163 \mathrm{~mm} \mathrm{~m}^{-1}$ de solo e no solo argiloso, de 116,2 $\mathrm{mm} \mathrm{m}^{-1}$ de solo.

Avaliando a Tabela 2, verifica-se que aos 15 dias após o plantio os substratos e os manejos hídricos de viveiro não influenciaram no percentual de plantas com sintoma brando de estresse hídrico nos dois solos onde foram plantadas, exceto para F4 em solo de textura arenosa, que apresentou valores estatisticamente diferentes entre os substratos, sendo as mudas no PLX com menor percentual desses sintomas. Isso pode indicar que o substrato PLX pode reter mais água, e isso ser significativo para as mudas nos primeiros dias

Tabela 1 - Média dos resultados da retenção de água nos dois solos.

Table 1 - Average values for the soil water retention.

\begin{tabular}{ccc}
\hline Tensão & \multicolumn{2}{c}{$\begin{array}{c}\text { Umidade do solo a base de } \\
\text { volume (\%) }\end{array}$} \\
\cline { 2 - 3 } & Textura Arenosa & Textura Argilosa \\
\hline Saturado & 46,80 & 66,67 \\
$-0,01 \mathrm{MPa}$ & 23,12 & 34,54 \\
$-0,03 \mathrm{MPa}$ & 22,33 & 33,14 \\
$-0,05 \mathrm{MPa}$ & 20,70 & 31,42 \\
$-0,1 \mathrm{MPa}$ & 19,07 & 28,41 \\
$-0,3 \mathrm{MPa}$ & 15,51 & 25,00 \\
$-0,5 \mathrm{MPa}$ & 9,26 & 23,14 \\
$-1,5 \mathrm{MPa}$ & 6,82 & 22,92 \\
Água disponível & 163 & 116,2 \\
(mm m $^{-1}$ solo) & & \\
\hline
\end{tabular}

após o plantio, principalmente para as que foram submetidas a um maior manejo hídrico, caso das submetidas à F4. Embora somente no solo arenoso tenha sido significativo, verifica-se que no solo argiloso os valores foram distintos (0,26 no PLX e 4,17 no CAC). Em função de o DMS ter sido alto, os valores foram estatisticamente semelhantes, porém de forma geral o DMS foi alto, pois fatores bióticos do meio como formigas (Atta sp. e Acromyrmex sp.), por exemplo, influenciaram os resultados.

A avaliação aos 30 dias mostrou pouca diferença em relação à anterior. As mudas sob o manejo F1 quando plantadas no solo argiloso apresentaram, estatisticamente, menor incidência dos sintomas quando produzidas no substrato PLX. No solo arenoso, as mudas de F2 produzidas em PLX foram estatisticamente superiores (sem sintoma), em comparação com as de CAC.

De acordo com a Tabela 3, aos 15 e aos 30 dias após o plantio o percentual de mudas com sintoma moderado de estresse hídrico no solo argiloso foi semelhante, independentemente do manejo hídrico. As plantas produzidas no substrato CAC sob os manejos F1 e FD (situações estressantes, pela falta e disponibildade total de água, respectivamente) foram significativamente mais afetadas do que as mudas produzidas no substrato PLX. No solo arenoso, o manejo hídrico não influenciou o aparecimento desses sintomas nas mudas produzidas no substrato PLX. Nas mudas do substrato CAC, o manejo F4 resultou na maior \% de plantas afetadas, embora semelhantes estatisticamente às sob manejos F2 e FD. Nas mudas do substrato CAC aos 30 dias, os sintomas foram mais perceptíveis do que nas do substrato PLX, sob o manejo F1, independentemente do solo onde tenham sido plantadas. Sob a condição FD, somente no solo argiloso após 30 dias do plantio as mudas produzidas no substrato CAC foram significativamente mais afetadas do que as do substrato PLX.

Com relação aos sintomas severos de deficiência hídrica (Tabela 4), tanto nas mudas plantadas no solo arenoso quanto no argiloso os valores, após 15 e 30 dias do plantio, foram todos semelhantes estatisticamente, não sendo afetados pelo substrato e manejo hídrico de viveiro. Exceção ocorreu somente nas mudas do manejo FD, que foram menos afetadas quando produzidas no substrato PLX aos 30 dias. 
Tabela 2 - Porcentagem média de plantas afetadas nos solos de texturas argilosa e arenosa, com sintoma brando de déficit hídrico, aos 15 e aos 30 dias após o plantio, em função do substrato e do manejo hídrico de viveiro.

Table 2 - Average percent of plants affected in the clay texture and sandy soils, with mild symptoms of water stress after 15 and 30 days the planting, due to substrate and nursery water management.

\begin{tabular}{|c|c|c|c|c|c|c|}
\hline \multirow{4}{*}{$\begin{array}{l}\text { Manejo } \\
\text { Hídrico }\end{array}$} & \multicolumn{6}{|c|}{ Plantas afetadas aos 15 dias (\%) } \\
\hline & \multirow{2}{*}{\multicolumn{3}{|c|}{$\begin{array}{c}\text { Solo argiloso } \\
\text { Substrato }\end{array}$}} & \multicolumn{3}{|c|}{ Solo de textura arenosa } \\
\hline & & & & \multicolumn{3}{|c|}{ Substrato } \\
\hline & CAC & PLX & D.M.S. & CAC & PLX & D.M.S. \\
\hline F1 & 2,08 & 0,26 & 2,49 & 0,52 & 0,00 & 1,66 \\
\hline F2 & 4,17 & 0,52 & 6,42 & $2,86 \mathrm{~A}$ & $0,26 \mathrm{~B}$ & 1,66 \\
\hline F3 & 1,04 & 0,00 & 2,34 & 4,17 & 0,26 & 4,95 \\
\hline F4 & 4,17 & 0,26 & 6,40 & $2,60 \mathrm{~A}$ & $0,52 \mathrm{~B}$ & 1,91 \\
\hline FD & 1,56 & 1,04 & 3,45 & 1,56 & 0,00 & 2,87 \\
\hline \multirow[t]{2}{*}{ D.M.S. } & 6,15 & 1,56 & & 3,95 & 0,88 & \\
\hline & \multicolumn{6}{|c|}{ Plantas afetadas aos 30 dias (\%) } \\
\hline F1 & $2,34 \mathrm{~A}$ & $0,52 \mathrm{~B}$ & 0,83 & 0,52 & 0,00 & 1,66 \\
\hline F2 & 3,65 & 0,26 & 5,80 & $2,08 \mathrm{~A}$ & $0,0 \mathrm{~B}$ & 0,00 \\
\hline F3 & 2,08 & 0,26 & 2,83 & 3,91 & 0,26 & 5,15 \\
\hline F4 & 3,12 & 0,00 & 4,28 & $2,60 \mathrm{~A}$ & $0,52 \mathrm{~B}$ & 1,91 \\
\hline FD & 1,04 & 1,60 & 3,45 & 1,30 & 0,00 & 3,14 \\
\hline D.M.S. & 5,12 & 2,40 & & 3,85 & 0,74 & \\
\hline
\end{tabular}

$\left.{ }^{(}\right)$D.M.S. - Diferença mínima estatística do teste de Tukey $(\alpha=5 \%)$. Médias seguidas de letras minúsculas iguais na mesma coluna e maiúsculas iguais na mesma linha no mesmo solo não diferem entre si, pelo teste de Tukey a 5\% de significância.

Tabela 3 - Porcentagem média de plantas afetadas, nos solos de texturas argilosa e arenosa, com sintoma moderado de déficit hídrico, aos 15 e aos 30 dias após o plantio, em função do substrato e do manejo hídrico de viveiro.

Table 3 -Average percent of plants affected in the clay texture and sandy soils, with moderate symptoms of water stress 15 and 30 days after the planting, due to substrate and nursery water management.

\begin{tabular}{|c|c|c|c|c|c|c|}
\hline \multirow{4}{*}{$\begin{array}{l}\text { Manejo } \\
\text { Hídrico }\end{array}$} & \multicolumn{6}{|c|}{ Plantas afetadas aos 15 dias (\%) } \\
\hline & \multicolumn{3}{|c|}{ Solo de textura argilosa } & \multicolumn{3}{|c|}{ Solo de textura arenosa } \\
\hline & \multicolumn{3}{|c|}{ Substrato } & \multicolumn{3}{|c|}{ Substrato } \\
\hline & CAC & PLX & D.M.S. & CAC & PLX & D.M.S. \\
\hline F1 & 2,60 & 0,26 & 2,83 & $1,82 \mathrm{Ab}$ & $0,00 \mathrm{~B}$ & 1,59 \\
\hline F2 & 4,69 & 0,52 & 8,23 & $2,86 \mathrm{ab}$ & 1,82 & 7,03 \\
\hline F3 & 4,17 & 1,56 & 4,97 & $1,82 \mathrm{Ab}$ & $0,52 \mathrm{~B}$ & 0,83 \\
\hline F4 & 6,51 & 1,04 & 6,95 & $5,47 \mathrm{Aa}$ & $0,26 \mathrm{~B}$ & 3,32 \\
\hline FD & $6,77 \mathrm{~A}$ & $0,78 \mathrm{~B}$ & 3,42 & $2,08 \mathrm{ab}$ & 0,26 & 2,83 \\
\hline D.M.S. & 7,44 & 2,09 & & 3,53 & 1,90 & \\
\hline \multicolumn{7}{|c|}{ Plantas afetadas aos 30 dias (\%) } \\
\hline F1 & $2,60 \mathrm{~A}$ & $0,26 \mathrm{~B}$ & 1,59 & $1,56 \mathrm{Ab}$ & $0,00 \mathrm{~B}$ & 0,96 \\
\hline F2 & 3,39 & 0,52 & 6,82 & $1,82 \mathrm{ab}$ & 1,56 & 4,36 \\
\hline F3 & 5,21 & 0,52 & 5,15 & $1,30 \mathrm{~b}$ & 0,26 & 1,35 \\
\hline F4 & 4,17 & 2,60 & 6,70 & 4,95 $\mathrm{Aa}$ & $0,26 \mathrm{~B}$ & 3,94 \\
\hline FD & $5,21 \mathrm{~A}$ & 0,52 B & 1,66 & $2,08 \mathrm{ab}$ & 0,00 & 2,34 \\
\hline D.M.S. & 5,81 & 3,72 & & 3,14 & 1,62 & \\
\hline
\end{tabular}

${ }^{(1)}$ D.M.S. - Diferença mínima estatística do teste de Tukey $(\mathrm{a}=5 \%)$. Médias seguidas de letras minúsculas iguais na mesma coluna e maiúsculas iguais na mesma linha no mesmo solo não diferem entre si, pelo teste de Tukey a 5\% de significância.

Analisando o percentual de plantas afetadas por sintomas de deficiência hídrica (Tabela 5), verifica-se que os níveis brando e severo não foram influenciados pelo tipo de substrato usado na produção de mudas nos dois solos em que foram plantadas. O nível moderado só foi diferente nos solos arenoso e argiloso quando utilizado o substrato CAC na produção das mudas, sendo estas menos afetadas quando plantadas no solo 
Tabela 4 - Porcentagem média de plantas afetadas nos solos de texturas argilosa e arenosa, com sintoma severo de déficit hídrico, aos 15 e aos 30 dias após o plantio, em função do substrato e do manejo hídrico de viveiro.

Table 4 - Average percent of plants affected in the clay texture and sandy soils, with severe symptoms after of water stress 15 and 30 days after the planting, due to substrate and nursery water management.

\begin{tabular}{|c|c|c|c|c|c|c|}
\hline \multirow{2}{*}{$\begin{array}{l}\text { Manejo } \\
\text { Hídrico }\end{array}$} & \multicolumn{6}{|c|}{ Plantas afetadas aos 15 dias (\%) } \\
\hline & \multicolumn{3}{|c|}{ Solo de textura argilosa } & \multicolumn{3}{|c|}{ Solo de textura arenosa } \\
\hline & \multicolumn{3}{|c|}{ Substrato } & \multicolumn{3}{|c|}{ Substrato } \\
\hline & CAC & PLX & D.M.S. & CAC & PLX & D.M.S. \\
\hline F1 & 1,04 & 0,52 & 3,17 & 4,17 & 0,26 & 5,96 \\
\hline F2 & 2,34 & 1,30 & 4,06 & 2,60 & 1,30 & 2,09 \\
\hline F3 & 8,07 & 1,56 & 8,49 & 2,86 & 0,26 & 3,95 \\
\hline F4 & 6,25 & 1,82 & 7,34 & 3,39 & 0,78 & 3,45 \\
\hline FD & 7,81 & 1,04 & 7,94 & 3,12 & 0,78 & 4,36 \\
\hline \multirow[t]{2}{*}{ D.M.S. } & 9,32 & 2,70 & & 5,84 & 1,92 & \\
\hline & \multicolumn{6}{|c|}{ Plantas afetadas aos 30 dias (\%) } \\
\hline F1 & 1,04 & 0,52 & 3,17 & 2,86 & 0,78 & 3,58 \\
\hline F2 & 1,30 & 0,52 & 2,83 & 2,34 & 0,73 & 2,14 \\
\hline F3 & 3,91 & 1,04 & 4,76 & 1,82 & 0,26 & 2,14 \\
\hline F4 & 3,91 & 0,52 & 5,48 & 2,08 & 1,04 & 3,58 \\
\hline FD & $5,47 \mathrm{~A}$ & $1,04 \mathrm{~B}$ & 4,14 & $2,34 \mathrm{~A}$ & $0,52 \mathrm{~B}$ & 1,59 \\
\hline D.M.S. & 6,04 & 2,27 & & 3,82 & 2,49 & \\
\hline
\end{tabular}

( $\left.{ }^{1}\right)$ D.M.S. - Diferença mínima estatística do teste de Tukey $(\mathrm{a}=5 \%)$. Médias seguidas de letras minúsculas iguais na mesma coluna e maiúsculasiguais na mesma linha no mesmo solo não diferem entre si, pelo teste de Tukey a 5\% de significância.

Tabela 5 - Porcentagem média de plantas afetadas com os sintomas de déficit hídrico, aos 15 e aos 30 dias após o plantio, nos substratos em função do solo.

Table 5 - Average percent of plants affected with water stress 15 and 30 days after the planting, for the substrates do due soil.

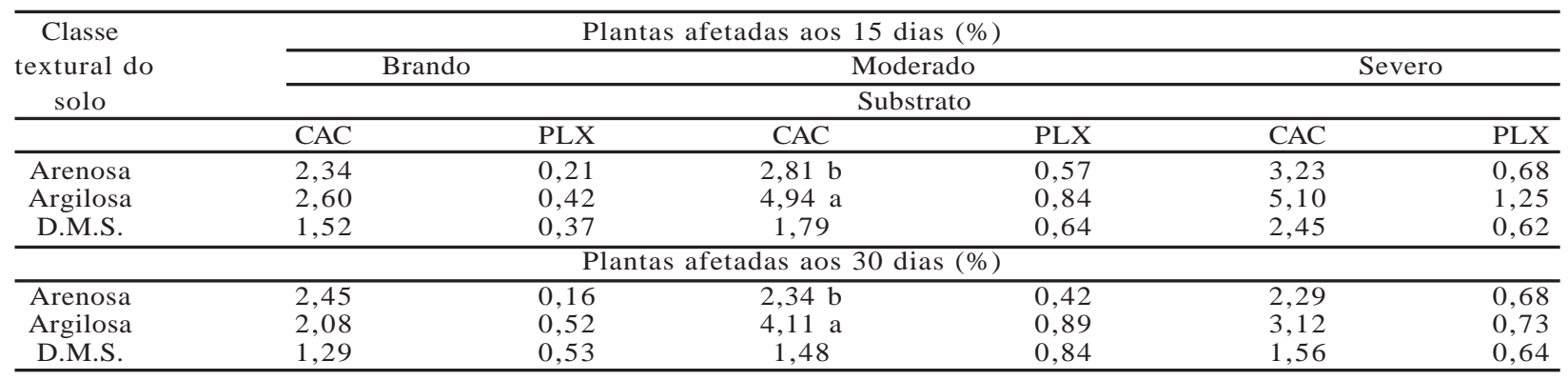

D.M.S. - Diferença mínima estatística do teste de Tukey $(\alpha=5 \%)$. Médias seguidas de letras minúsculas iguais na mesma coluna não diferem entre si, pelo teste de Tukey a 5\% de significância.

De acordo com a Tabela 6, a mortalidade das plantas no solo arenoso não sofreu influência do substrato usado na produção e do manejo hídrico aplicado às mudas. No solo argiloso, as mudas produzidas no PLX garantiram melhor sobrevivência aos 15 dias após o plantio, mas a avaliação aos 30 dias mostrou que esse efeito desapareceu, ficando somente as mudas do manejo F1 estatisticamente melhores no substrato PLX que no CAC. Porém, as mudas submetidas aos demais manejos hídricos comportaram-se de modo semelhante no campo.

Revista Árvore, Viçosa-MG, v.35, n.1, p.31-39, 2011
Para determinação da necessidade de replantio, os dados da avaliação até 30 dias são geralmente os mais usados na silvicultura. Os percentuais de mortalidade considerados variam entre empresas, pois dependem da análise de vários fatores, mas, de forma geral, acima de uma faixa que varia de 2 a 5\% (dependem da lotação por hectare e do material genético, principalmente) já há indicação de replantio. Ao analisar os valores desta pesquisa, observou-se que, a partir desse critério, nas duas situações de campo houve necessidade de 
Tabela 6 - Porcentagem média de plantas mortas por estresse hídrico, aos 15 e aos 30 dias após o plantio, em função do manejo hídrico e do substrato.

Table 6 - Average percent of plants dead by water stress 15 and 30 days after the planting, due to water management and substrate.

\begin{tabular}{|c|c|c|c|c|c|c|}
\hline \multirow{3}{*}{$\begin{array}{l}\text { Manejo } \\
\text { hídrico de } \\
\text { viveiro }\end{array}$} & \multicolumn{5}{|c|}{ Plantas mortas por déficit hídrico aos 15 dias (\%) } & \\
\hline & \multicolumn{3}{|c|}{ Solo de textura argilosa } & \multicolumn{3}{|c|}{ Solo de textura arenosa } \\
\hline & \multicolumn{6}{|c|}{ Substrato } \\
\hline & CAC & PLX & D.M.S. & CAC & PLX & D.M.S. \\
\hline F1 & $9,90 \mathrm{~A}$ & $1,53 \mathrm{~B}$ & 8,01 & 5,47 & 0,52 & 6,26 \\
\hline $\mathrm{F} 2$ & $10,15 \mathrm{~A}$ & $2,34 \mathrm{~B}$ & 2,87 & 0,78 & 0,52 & 1,59 \\
\hline F3 & 8,56 & 6,51 & 11,40 & 1,30 & 1,04 & 1,59 \\
\hline F4 & 5,21 & 5,47 & 5,31 & 1,82 & 1,04 & 1,59 \\
\hline FD & $14,32 \mathrm{~A}$ & $1,82 \mathrm{~B}$ & 10,22 & 1,82 & 0,52 & 5,31 \\
\hline D.M.S. & 12,95 & 6,87 & & 5,39 & 1,71 & \\
\hline \multicolumn{7}{|c|}{ Plantas mortas por déficit hídrico aos 30 dias (\%) } \\
\hline F1 & 16,67 Aab & $4,95 \mathrm{~B}$ & 2,49 & $14,06 \mathrm{~A}$ & 4,95 Ba & 6,82 \\
\hline F2 & $7,55 \mathrm{~b}$ & 5,47 & 10,40 & 6,50 & 8,59 & 7,03 \\
\hline F3 & $15,89 a b$ & 7,03 & 9,90 & 11,98 & 7,03 & 5,31 \\
\hline F4 & $9,64 \mathrm{ab}$ & 12,50 & 8,60 & 6,50 & 10,15 & 7,83 \\
\hline FD & 19,79 а & 10,16 & 12,28 & 7,03 & 8,33 & 11,11 \\
\hline D.M.S. & 11,38 & 10,65 & & 7,79 & 6,96 & \\
\hline
\end{tabular}

D.M.S. - Diferença mínima estatística do teste de Tukey (a = 5\%). Médias seguidas de letras minúsculas iguais na mesma coluna e iguais na mesma coluna no mesmo solo não diferem entre si, pelo teste de Tukey a 5\% de significância.

replantio. Os manejos aplicados às mudas durante o seu processo de produção tiveram influência inferior à dos fatores inerentes às atividades silviculturais relativas à implantação da floresta corroborando as preocupações de Lopes (2004), que abordou, entre outros aspectos, o tempo excessivo que as mudas permanecem encaixotadas e mantidas à sombra e com a própria qualidade do plantio.

Os resultados desta pesquisa refletem as informações da literatura. A composição do ar do solo sofre alterações constantes com a infiltração de água, com as mudanças da atmosfera em conexão com as flutuações diárias de temperatura e com a velocidade do vento (KLAR, 1991). Isso, conjuntamente com as atuais técnicas de plantio do eucalipto, parece fazer sobressair a qualidade das mudas que foram alcançadas pelo manejo de viveiro e a atribuída "rusticidade” na garantia da sobrevivência (LOPES, 2008). Neste experimento, verificou-se que a aclimatação desejada como critério para rusticidade e garantia de sobrevivência em campo não foi alcançada. É possível que o período de rustificação não tenha sido suficiente para que tivesse ocorrido a aclimatação ou que o clone usado nesta pesquisa, H13, não tenha conseguido se tornar mais eficiente na absorção de água do solo, através do desenvolvimento extenso e profundo das raízes, ou através de características da parte aérea: área foliar, rápido fechamento dos estômatos e manutenção de temperaturas foliares reduzidas, entre outras, como citaram Li et al. (2000) e Chaves et al. (2004).

Segundo Mafia et al. (2005), porém, a manutenção de mudas por maiores períodos no viveiro tende a diminuir a velocidade de crescimento e induzir malformações radiculares. Nesse sentido, Neves (2004) mencionou que várias empresas já abandonaram essa técnica, que é muito questionada inclusive, porque, além de a adaptação estar mais relacionada com os processos genéticos (TAIZ e ZEIGER, 2004), a aclimatação (através de manejos hídricos) interfere em vários processos fisiológicos, que por sua vez também interferem na absorção dos nutrientes.

Alguns materiais genéticos que se adaptam à variabilidade de disponibilidade hídrica e que apresentam as características desejáveis para a produção em escala já foram desenvolvidos através do melhoramento genético de espécies, o entanto, as etapas que envolvem a seleção costumam levar alguns anos até a comprovação final (LELES et al., 1998). Nesse sentido, Chaves et al. (2004) verificaram que a condutância estomática não sofreu influência em função do manejo hídrico. Mudas mantidas na capacidade de campo e mudas sob diferentes níveis de déficit hídrico apresentaram o mesmo comportamento.

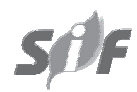

Revista Árvore, Viçosa-MG, v.35, n.1, p.31-39, 2011 
Esses autores sugeriram que sejam necessários de quatro a cinco ciclos de seca para que haja "adaptação" (aclimatação) das mudas, o que, consequentemente, seria benéfico em termos de sobrevivência no campo. Contudo, este experimento não avaliou o desempenho das mudas em campo.

Os avanços no estudo da eficiência do uso da água em eucalipto têm demonstrado que o gênero possui mecanismos fisiológicos que regulam a absorção e perda de água, influenciando diretamente a produtividade florestal (STAPE et al., 2004). Vários outros autores sugerem que a aclimatação das mudas com água, durante as fases de viveiro (crescimento e, principalmente, rustificação), aumentaria a sobrevivência delas em campo (SILVA, 1998; SILVA, 2003; CHAVES etal., 2004; LOPES, 2004; PEREIRA, 2006; TATAGIBA, 2006; FREITAG 2007; MARTINS, 2007). No entanto, nessas pesquisas não foram comprovados ou até mesmo, na maioria delas, testados os níveis dos estresses hídricos em campo, bem como sua relação com a necessidade de replantio. Silva (2003) verificou que o manejo nutricional foi mais efetivo na sobrevivência das mudas que o manejo hídrico. Nesse sentido, podese inferir que a aclimatação de mudas utilizando o manejo hídrico não seja a técnica mais adequada para garantir a sobrevivência das mudas em campo e, corroborando Taiz e Zeiger (2004), atribuir ao melhoramento genético a adaptação das mudas. Dessa maneira, os critérios usados na implantação contribuíram de modo mais acentuado do que o manejo hídrico de viveiro, uma vez que a nutrição das mudas também parece não ter interferido, já que no CAC foi melhor do que no PLX (LOPES, 2008).

\section{CONCLUSÃO}

Com relação aos níveis de estresse avaliados, verificou-se pouca influência do substrato, porém onde ocorreu o PLX houve menores percentuais de plantas afetadas.

Independentemente do tipo de solo onde as mudas foram plantadas, os sintomas de estresse nas plantas, de modo geral, foram semelhantes.

O manejo de viveiro não influenciou na sobrevivência das mudas, embora tenham ocorrido algumas diferenças estatísticas quando se usaram CAC e o plantio em solo TA, porém sem tendência clara de comportamento. Esses resultados indicaram que os fatores relativos à implantação possam ser mais determinantes na sobrevivência das mudas no campo até os 30 dias após o plantio, o que refletiu na necessidade de replantio.

\section{AGRADECIMENTOS}

Ao CNPq, pela bolsa concedida ao primeiro autor.

Às empresas Camará - Viveiros Florestais, Eucatex Mineral, Eucatex Florestal e Imirá Agroflorestal, pela infraestrutura.

À UNESP/FCA, pelas análises realizadas.

\section{REFERÊNCIAS}

CHAVES, J. H. et al. Seleção precoce de clones de eucalipto para ambientes com disponibilidade diferenciada de água no solo. Relações hídricas de plantas em tubetes. Revista Árvore, v.28, n.3, p.333-341, 2004.

FERREIRA, F. A.; MILANI, D. Diagnose visual e controle das doenças abióticas e bióticas do eucalipto no Brasil. Mogi Guaçu: International Paper, 2002. 98p.

FREITAG, A. S. Freqüências de irrigação para Eucalyptus grandis e Pinus elliotti em viveiro. 2007. 60f. Dissertação (Mestrado em Engenharia Agrícola) - Universidade Federal de Santa Maria, Santa Maria, 2007.

GONÇALVES, J. L. M. Recomendações de adubação para Eucalyptus, Pinus e espécies típicas da mata atlântica. Piracicaba: Departamento de Ciências Florestais da Escola Superior de Agricultura Luiz de Queiroz - Universidade de São Paulo, 1995. p.1-23 (Documentos Florestais, 15).

GONÇALVES, J. L. M. et al. Reflexos do cultivo mínimo e intensivo do solo em sua fertilidade e na nutrição das árvores. In: GONÇALVES, J. L. M.; STAPE, J. L., (Eds.) Nutrição e fertilização florestal. Piracicaba: IPEF, 2000. p.3-55.

KLAR, A. E. Irrigação - Freqüência e quantidade de aplicação. São Paulo: Nobel, 1991. 156p.

LARCHER, W. Plantas sob estresse. In:

LARCHER, W. Ecofisiologia vegetal. São Carlos: Rima, 2000. p.341-430.

LELES, P. S. S. et al. Relações hídricas e crescimento de árvores de Eucalyptus camaldulensis e Eucalyptus pellita sob diferentes espaçamentos na região de cerrado. Revista Árvore, v.22, n.1, p.41-50, 1998. 
LI, C. et al. Drought responses of Eucalyptus microtheca provenances depend on seasonality of rainfall in their place of origin. Australian Journal of Plant Physiology, v.27, n.3, p.231-238. 2000.

LOPES, J. L. W. Produção de mudas de Eucalyptus grandis W. (Hill ex. Maiden) em diferentes substratos e lâminas de irrigação. 2004. 100f. Dissertação (Mestrado em Agronomia-Irrigação e Drenagem) - Faculdade de Ciências Agronômicas, Universidade Estadual Paulista, Botucatu, 2004.

LOPES, J. L. W. Qualidade de mudas clonais do híbrido Eucalyptus grandis vs. Eucalyptus urophylla, submetidas a diferentes regimes hídricos. 2008. 171f. Tese (Doutorado em Agronomia - Irrigação e Drenagem) - Faculdade de Ciências Agronômicas, Universidade Estadual Paulista, Botucatu, 2008.

LOPES, J. L. W. et al. Influência dos fatores bióticos e abióticos na sobrevivência de eucalipto em função do solo e do manejo hídrico de viveiro. Biotemas, v.22, n.2, p.29-38, 2009.

MAFIA, R. G. et al. Critério técnico para determinação da idade ótima de mudas de eucalipto para plantio. Revista Árvore, v.29, n.6, p.947-953, 2005.

MARTINS, F. B. Desenvolvimento e estresse hídrico em mudas de Eucalyptus grandis (Hill ex Maiden) e Eucalyptus saligna (Smith). 2007. 73f. Dissertação (Mestrado em Engenharia Agrícola) Universidade Federal de Santa Maria, Santa Maria, 2007.

MERCHANT, A. et al. Contrasting physiological response of six Eucalyptus species to water deficit. Annals of Botany, v.100, n.7, p.15071515, 2007.

NEVES, J. C. L. Doses e modos de localização dos nutrientes em recipientes contendo volumes variáveis de substrato. In: ENCONTRO NACIONAL SOBRE SUBSTRATO PARA PLANTAS, 4., 2004, Viçosa. Anais...Viçosa, MG: Universidade Federal de Viçosa, 2004. (Palestra não disponibilizada).
PEREIRA, M. R. R. Comportamento

fisiológico e morfológico de clones de Eucalyptus sp. W. (Hill ex Maiden) submetidas a diferentes níveis de água no solo. 2006. 69f. Dissertação (Mestrado em Agronomia - Irrigação e Drenagem) - Faculdade de Ciências Agronômicas, Universidade Estadual Paulista, Botucatu, 2006.

RICHARDS, L. A. Methods of measuring soil misture tension. Soil Science, v.68, p.95-112, 1949.

SILVA, M. R. Caracterização morfológica, fisiológica e nutricional de mudas de Eucalyptus grandis W. (HILL ex MAIDEN) submetidas a diferentes níveis de estresse hídrico durante a fase de rustificação. 1998. 105f. Dissertação (Mestrado em Ciências Agrárias) - Universidade Federal do Paraná, Curitiba, 1998.

SILVA, M. R. Efeitos do manejo hídrico e da aplicação de potássio na qualidade de mudas de Eucalyptus grandis W. (Hill ex. Maiden). 2003. 100f. Tese (Doutorado em Agronomia - Irrigação e Drenagem) - Faculdade de Ciências Agronômicas, Universidade Estadual Paulista, Botucatu, 2003.

STAPE, J. L.; BINKLEY, D.; RYAN, M. G. Eucalyptus production and the supply, use and efficiency of use of water, light and nitrogen across a geographic gradient in Brazil. Forest Ecology and Management, v.193, p.17-31, 2004.

TATAGIBA, S. D. Crescimento inicial, trocas gasosas e status hídrico de clones de eucalipto sob diferentes regimes de irrigação. 2006. 128f. Dissertação (Mestrado em Ciências Agrárias Produção Vegetal) - Universidade Federal do Espírito Santo, Alegre, 2006.

TATAGIBA, S. D. et al. Comportamento fisiológico de dois clones de Eucalyptus na época seca e chuvosa. Cerne, v.13, n.2, p.149-159, 2007.

TAIZ, L.; ZEIGER, E. Fisiologia do estresse. In: SANTAREM, E. R. et al. Fisiologia vegetal. 3.ed. Porto Alegre: Artmed, 2004. p.613-641.

Revista Árvore, Viçosa-MG, v.35, n.1, p.31-39, 2011 
